\title{
Regulation of Enteric Endophytic Bacterial Colonization by Plant Defenses
}

\author{
A. Leonardo Iniguez, ${ }^{1}$ Yuemei Dong, ${ }^{1}$ Heather D. Carter, ${ }^{2}$ Brian M. M. Ahmer, ${ }^{2}$ Julie M. Stone,${ }^{3}$ and \\ Eric W. Triplett ${ }^{4}$ \\ ${ }^{1}$ University of Wisconsin-Madison, Department of Agronomy, 1575 Linden Drive, Madison 53706 U.S.A.; ${ }^{2}$ The Ohio State \\ University, Department of Microbiology, 484 West 12 th Ave. Columbus 43210 U.S.A.; ${ }^{3}$ University of Nebraska-Lincoln, \\ Department of Biochemistry, 1901 Vine St., Lincoln 68588-0664 U.S.A.; ${ }^{4}$ University of Florida, Department of Microbiology \\ and Cell Science, P.O. Box 110700, Gainesville 32611-0700 U.S.A.
}

Submitted 14 May 2004. Accepted 25 October 2004.

Bacterial endophytes reside within the interior of plants without causing disease or forming symbiotic structures. Some endophytes, such as Klebsiella pneumoniae 342 (Kp342), enhance plant growth and nutrition. Others, such as Salmonella enterica serovar Typhimurium (S. typhimurium), are human pathogens that contaminate raw produce. Several lines of evidence are presented here to support the hypothesis that plant defense response pathways regulate colonization by endophytic bacteria. An ethyleneinsensitive mutant of Medicago truncatula is hypercolonized by Kp342 compared to the parent genotype. Addition of ethylene, a signal molecule for induced systemic resistance in plants, decreased endophytic colonization in Medicago spp. This ethylene-mediated inhibition of endophytic colonization was reversed by addition of the ethylene action inhibitor, 1-methylcyclopropene. Colonization of Medicago spp. by $S$. typhimurium also was affected by exogenous ethylene. Mutants lacking flagella or a component of the type III secretion system of Salmonella pathogenicity island 1 (TTSS-SPI1) colonize the interior of Medicago spp. in higher numbers than the wild type. Arabidopsis defense response-related genotypes indicated that only salicylic acid (SA)-independent defense responses contribute to restricting colonization by Kp342. In contrast, colonization by $S$. typhimurium is affected by both SA-dependent and -independent responses. $S$. typhimurium mutants further delineated these responses, suggesting that both flagella and TTSS-SPI1 effectors can be recognized. Flagella act primarily through $\mathrm{SA}$-independent responses (compromising $\mathrm{SA}$ accumulation still affected colonization in the absence of flagella). Removal of a TTSS-SPI1 effector resulted in hypercolonization regardless of whether the genotype was affected in either SA-dependent or SA-independent responses. Consistent with these results, $S$. typhimurium activates the promoter of PR1, a SA-dependent pathogenesisrelated gene, while $S$. typhimurium mutants lacking the TTSS-SPI1 failed to activate this promoter. These observations suggest approaches to reduce contamination of raw produce by human enteric pathogens and to increase the number of growth-promoting bacteria in plants.

Additional keywords: food safety, nitrogen fixation.

Corresponding author: Eric W. Triplett; Telephone: 352-392-5430; Fax: 352-392-5922; E-mail: ewt@ufl.edu

Current address of Y. Dong: Johns Hopkins University, Department of Molecular Microbiology \& Immunology, 615 Wolfe St., Baltimore, MD 21205 U.S.A.
Bacteria interact with plants in four ways, as pathogens, symbionts, epiphytes, or endophytes. Of these four types of bacteria-plant interactions, endophytic interactions are the least studied and least understood. Endophytes are defined here as bacteria that enter the interior of plants without causing disease symptoms or eliciting the formation of symbiotic structures. Endophytic bacteria are of agronomic interest because they can enhance plant growth and improve the nutrition of plants through nitrogen fixation (Boddey et al. 2003; Sevilla et al. 2001). They are also of medical interest because some bacterial endophytes are human pathogens that cannot effectively be removed by surface sterilization (Beuchat et al. 2001; Proctor et al. 2001; Taormina et al. 1999; Weissinger and Beuchat 2000; Weissinger et al. 2001).

In previous work, different species or strains of enteric bacteria were found to differ greatly in their ability to colonize the interior of Medicago sativa (alfalfa) roots (Dong et al. 2003a). However, the mechanism of this strain specificity is not known. A strain isolated from maize, Klebsiella pneumoniae 342 (Kp342), colonizes the interior of several host plants in higher numbers than any other strain tested (up to $10^{7}$ cells/g of fresh weight) (Dong et al. 2003a and b). This strain, originally isolated from a nitrogen-efficient maize line (Chelius and Triplett 2000), fixes $\mathrm{N}_{2}$ and increases maize yield in the field (Riggs et al. 2001). Kp342 also expresses nitrogenase in planta (Chelius and Triplett 2000) and occupies the interior of plants in much higher numbers than Klebsiella spp. that were not of plant origin (Dong et al. 2003a). Fewer than 10 cells of Kp342 are sufficient in the inoculum to fully colonize the plant (Dong et al. 2003a). Similarly various Salmonella strains differed in their ability to colonize alfalfa roots (Dong et al. 2003a). To understand this strain specificity, an in-depth analysis of the basic biology of endophytic colonization has begun to elucidate the mechanisms that allow specific bacterial strains to be successful endophytes. Here, four lines of evidence are presented in support of the hypothesis that plant defense response pathways regulate endophytic colonization.

\section{RESULTS}

Four lines of evidence suggest that plant defenses regulate the number of endophytic bacteria within plant tissues: i) ethylene, a signal molecule for induced systemic resistance in plants, decreases endophytic colonization; ii) presence of bacterial extracellular components decreases endophytic colonization; iii) increased endophytic colonization in host genotypes with diminished plant defense responses; and iv) activation of 
a promoter that controls an SA-dependent pathogenesis-related gene upon endophyte inoculation

Ethylene, a signal molecule for induced systemic resistance in plants, decreases endophytic colonization.

Ethylene has been studied extensively as a secondary messenger in the induction of a salicylic acid (SA)-independent plant defense pathway referred to as induced systemic resistance (ISR) (Knoester et al. 1998; Pieterse et al. 1998; Ton et al. 2001, 2002). Kp342 hypercolonized an ethylene-insensitive (sickle) mutant of M. truncatula (Fig. 1). This mutant also is hypernodulated following inoculation with the nitrogen-fixing symbiont Sinorhizobium meliloti (Penmetsa and Cook 1997). Consistent with this result, addition of the ethylene precursor, 1-aminocyclopropane-1-carboxylic acid (ACC), to the growth media significantly reduced endophytic colonization in wildtype $M$. sativa by Kp342 and Salmonella enterica serovar Typhimurium strain 14028 (S. typhimurium) by three and four orders of magnitude, respectively (Fig. 2). The number of Kp342 cells within $M$. truncatula roots does not change sig- nificantly with ACC treatment until 4 days after inoculation. This evidence suggests that ACC does not inhibit invasion of Kp342 cells into the plant but triggers a response that can significantly lower the number of Kp342 cells 4 days after ACC treatment (Fig. 3). To test the effects of ethylene on $M$. truncatula before, during, and after inoculation, a time-course experiment was conducted (Fig. 4). In this experiment, gaseous ethylene $\left(\mathrm{C}_{2} \mathrm{H}_{4}\right)$ was used rather than ACC because addition of $\mathrm{C}_{2} \mathrm{H}_{4}$ was required each day for up to 6 days during the time course. No difference in endophytic colonization was observed in plants exposed to $\mathrm{C}_{2} \mathrm{H}_{4}$ or $\mathrm{ACC}$ for the same time period (Fig. 4). This time course experiment showed that ethylene must be applied to the plants prior to or at the time of inoculation for maximal inhibition of endophytic colonization (Fig. 4). These results further corroborate those of Figure 3. That is, the effects of ethylene on endophytic colonization become significant $96 \mathrm{~h}$ after ethylene exposure. To determine whether ethylene affects endophytic colonization in monocots, wheat seedlings were exposed to varying amounts of ACC and inoculated with Kp342 and 14028 (Fig. 5). ACC caused a decline in
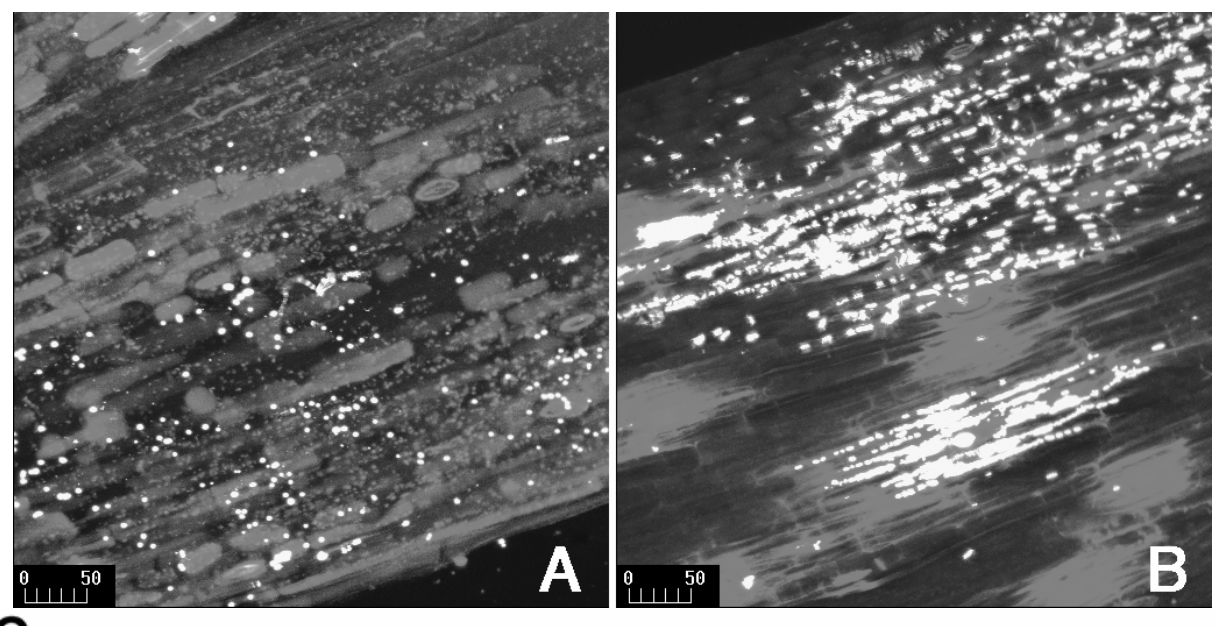

C

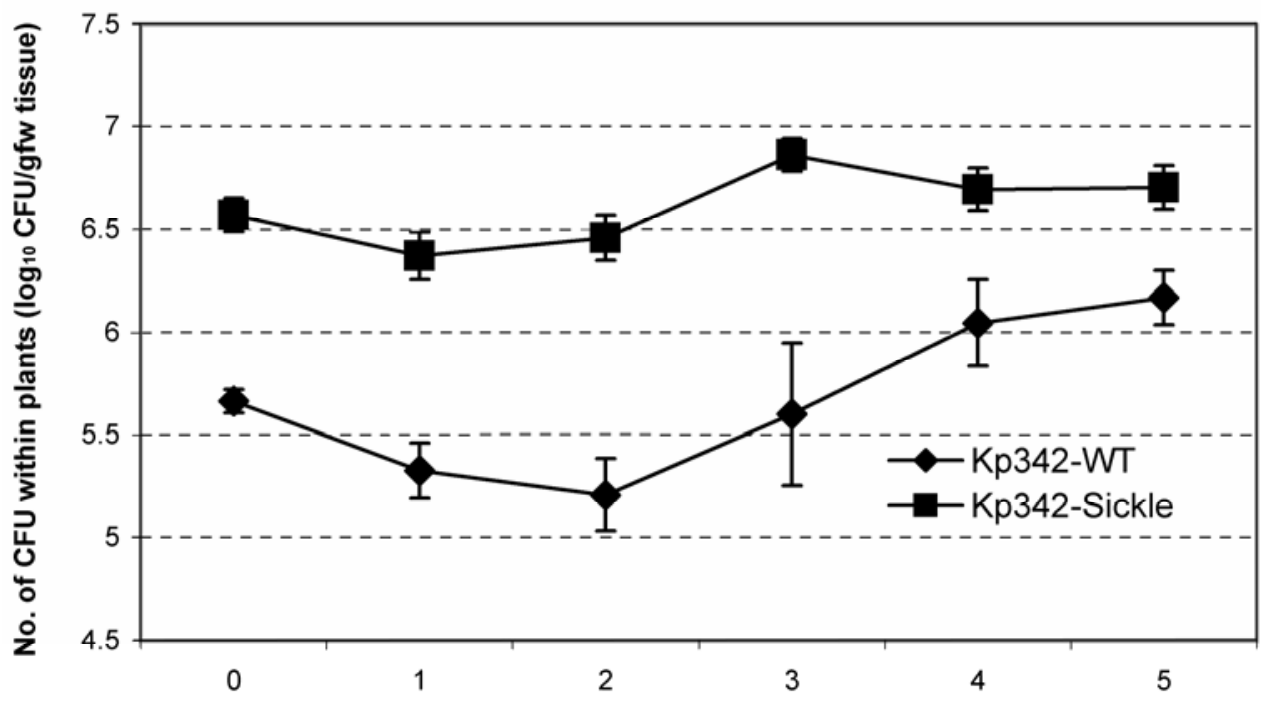

Inoculation level ( $\log _{10} \mathrm{CFU} /$ plant)

Fig. 1. Scanning laser confocal microscopy at $\times 20$ magnification of longitudinal sections of Medicago truncatula A, wild-type and B, sickle mutant hypocotyls showing colonization by green fluorescent protein-labeled Klebsiella pneumoniae 342 (Kp342). Sections were visualized 9 days after inoculation. The inoculum level was $10^{4} \mathrm{CFU} /$ plant. Bars, $50 \mu \mathrm{m}$. C, Numbers of bacterial CFU recovered from interior of M. truncatula Gaerten cv. A17 wild-type and sickle mutant plant tissues 7 days after inoculation. Two-day-old seedlings were inoculated with Kp342 at different inoculum levels. Data points represent the means and the bars represent the standard errors about the mean resulting from four replicates with each replicate consisting of four plants. 
the number of Kp342 and 14028 cells within wheat roots of 1.85 and 1.2 orders of magnitude, respectively (Fig. 5).

To confirm that the effects observed with ACC were specific to ethylene production, a specific inhibitor of ethylenemediated signaling, 1-methylcyclopropene (1-MCP) (Porat et al. 1999; Serek et al. 1995), reversed the reduction in endophytic colonization of alfalfa observed with ACC (Fig. 2). Also, treatment of plants with 1-MCP resulted in significantly higher endophytic colonization regardless of the presence or absence of exogenous ACC in M. truncatula (Fig. 2).
These results suggest that endogenously produced ethylene limits the extent of endophytic colonization in $M$. truncatula but not in $M$. sativa.

\section{Presence of bacterial extracellular components decreases endophytic colonization.}

Bacterial extracellular components, such as flagella, are known to induce plant defenses (Felix et al. 1999; GomezGomez and Boller 2000). A Salmonella 14028 mutant lacking both flagellin genes, $f l i C$ and $f l j B$, fails to produce flagella in

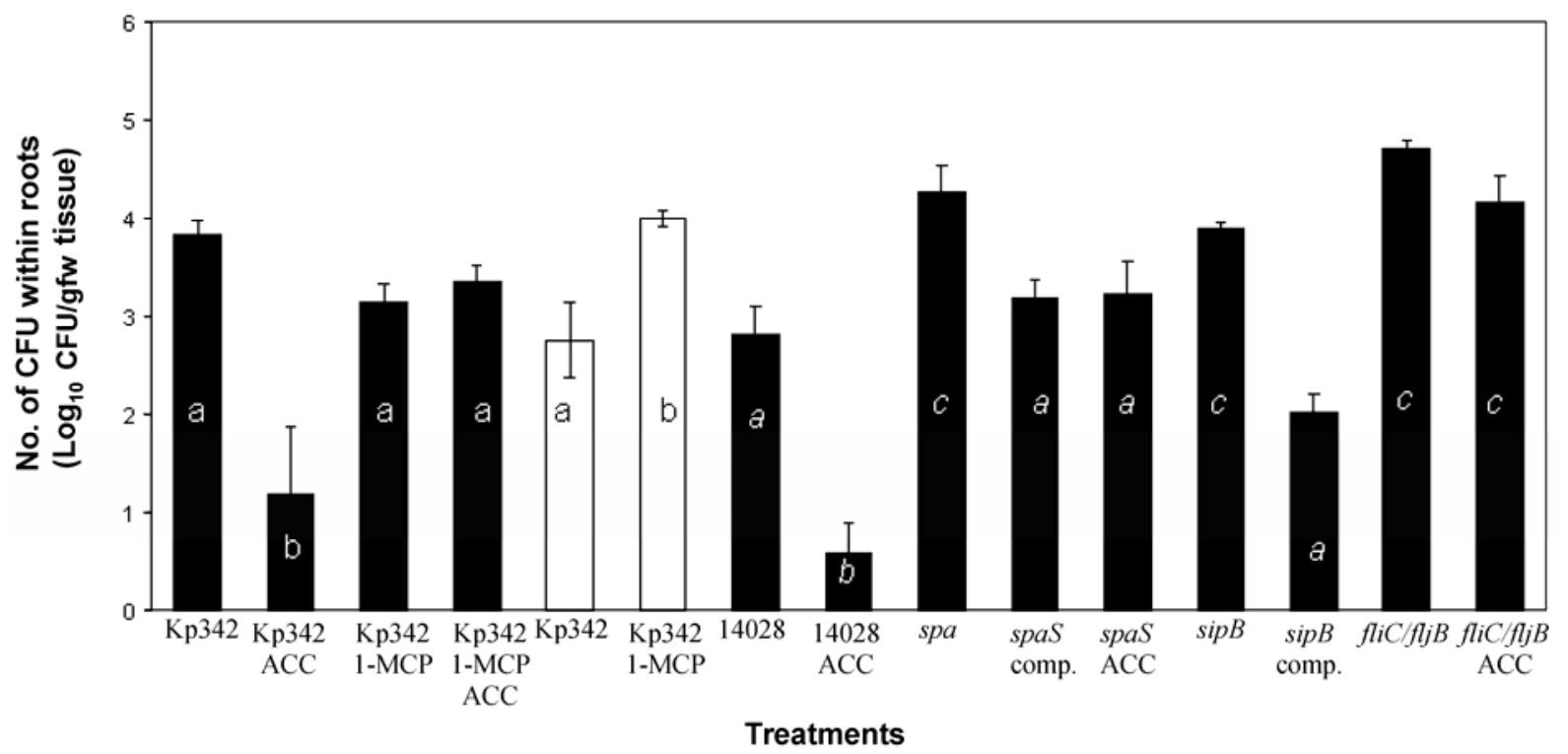

Fig. 2. Number of CFU recovered from the interior of Medicago sativa (closed columns) or M. truncatula (open columns) roots and hypocotyls were determined 5 and 7 days, respectively, post inoculation. Seedlings of M. truncatula were inoculated with $10^{2}$ CFU of Klebsiella pneumoniae 342 (Kp342) in the presence and absence of $1 \mathrm{ppm}$ of the ethylene action inhibitor, 1-methylcyclopropene (1-MCP). Seedlings of $M$. sativa were inoculated with Kp342, Salmonella enterica serovar Typhimurium strain 14028 (14028), the spaS mutant of 14028, the spaS mutant complemented with the spaS gene, the sipB mutant, the $\operatorname{sip} B$ mutant complemented with the $\operatorname{sip} B$ gene, and the double flagellin mutant with insertions in $f l i C$ and $f l j B$. Treatments included an untreated control, application of the ethylene precursor, $5 \mu \mathrm{M}$ 1-aminocyclopropane-1-carboxylic acid (ACC), or treatment with the ethylene action inhibitor, 1 ppm 1MCP. The bars represent the standard errors of the mean resulting from four replicates, each replicate consisting of four plants.

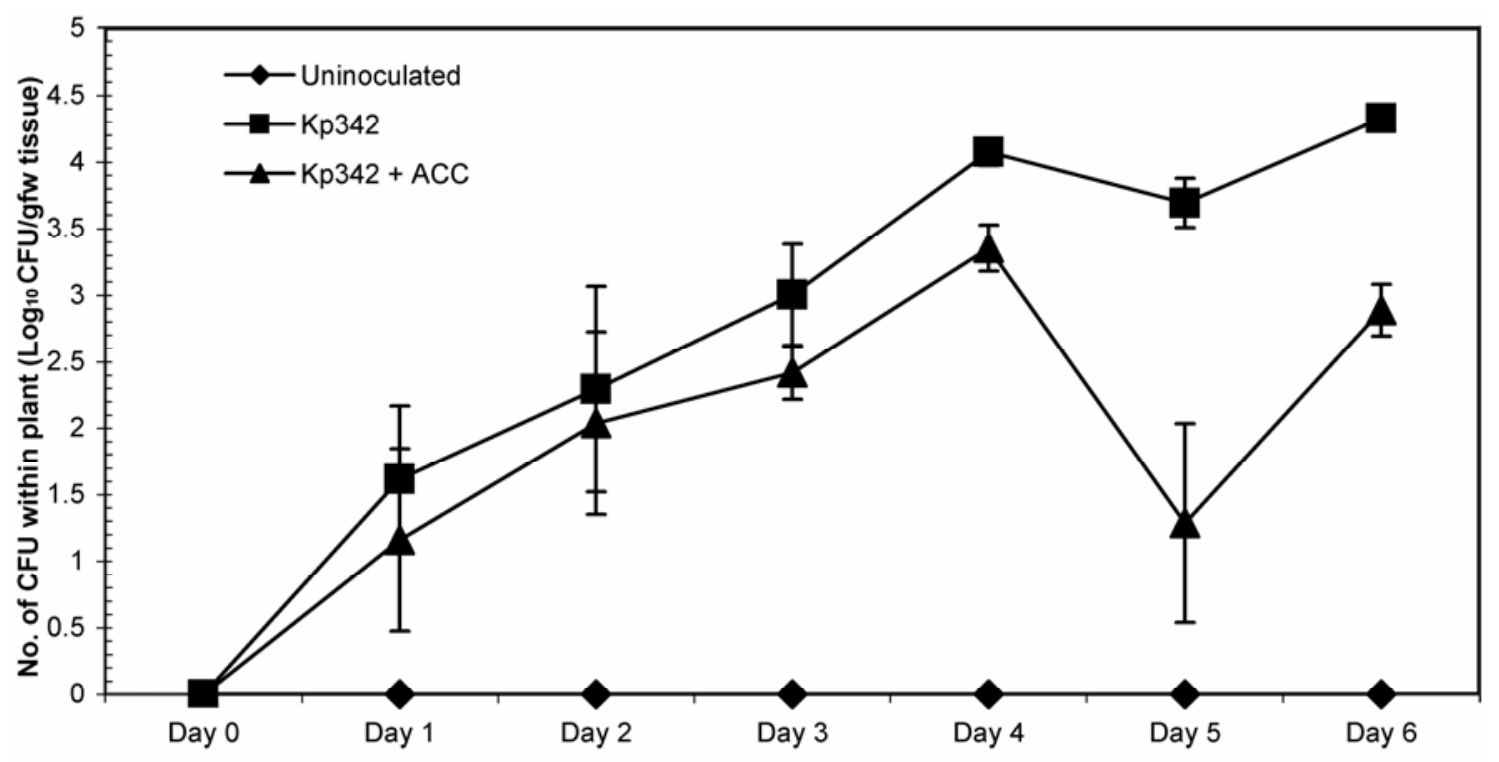

No. of days harvested after inoculation with $\mathrm{Kp} 342$

Fig. 3. Effect of 1-aminocyclopropane-1-carboxylic acid (ACC) on endophytic colonization over time. The number of CFU recovered from the interior of Medicago truncatula roots and hypocotyls was determined each day for 6 days after inoculation with $10^{2}$ cells of Klebsiella pneumoniae 342 (Kp342) per plant. Plants were treated with and without ACC $(5 \mu \mathrm{M})$ at the time of inoculation. The columns represent the mean CFU recovered from the plants, and the bars represent the standard errors of the means resulting from four replicate treatments; gfw = gram (fresh weight). ACC treatments are statistically different from the controls on days 4,5 , and 6 at the $5 \%$ level of confidence. 
culture. This mutant showed significantly higher endophytic colonization, consistent with the notion that Salmonella flagellar components are specifically recognized and induce plant defenses. Another extracellular component of enteric bacteria, the type III secretion system encoded by Salmonella pathogenicity island 1 (TTSS-SPI1), also affects endophytic colonization. The TTSS-SPI1 is a virulence factor that promotes invasion of mammalian cells and elicits fluid secretion and inflammation in animal models (Zhang et al. 2003). The sipB and spaS genes are encoded within SPI1. The spaS gene encodes a structural component of the type III secretion appara- tus, whereas the $\operatorname{sip} B$ gene encodes a protein with dual functions. SipB is required for translocation of other effectors and has effector properties of its own (Collazo and Galan 1997). Furthermore, secretion of SipB is independent of bacteria-host cell contact and, therefore, is not necessarily concomitant with translocation to host cells (Collazo and Galan 1997). Mutations in $\operatorname{spaS}$ and $\operatorname{sip} B$ resulted in much higher levels of colonization in alfalfa roots (Fig. 2). When these mutants were complemented with a wild-type copy of the gene, the reduced colonization phenotype was restored (Figs. 2). Similar results were obtained with the $\operatorname{sip} B$ mutant on wheat seedlings (Fig. 6).

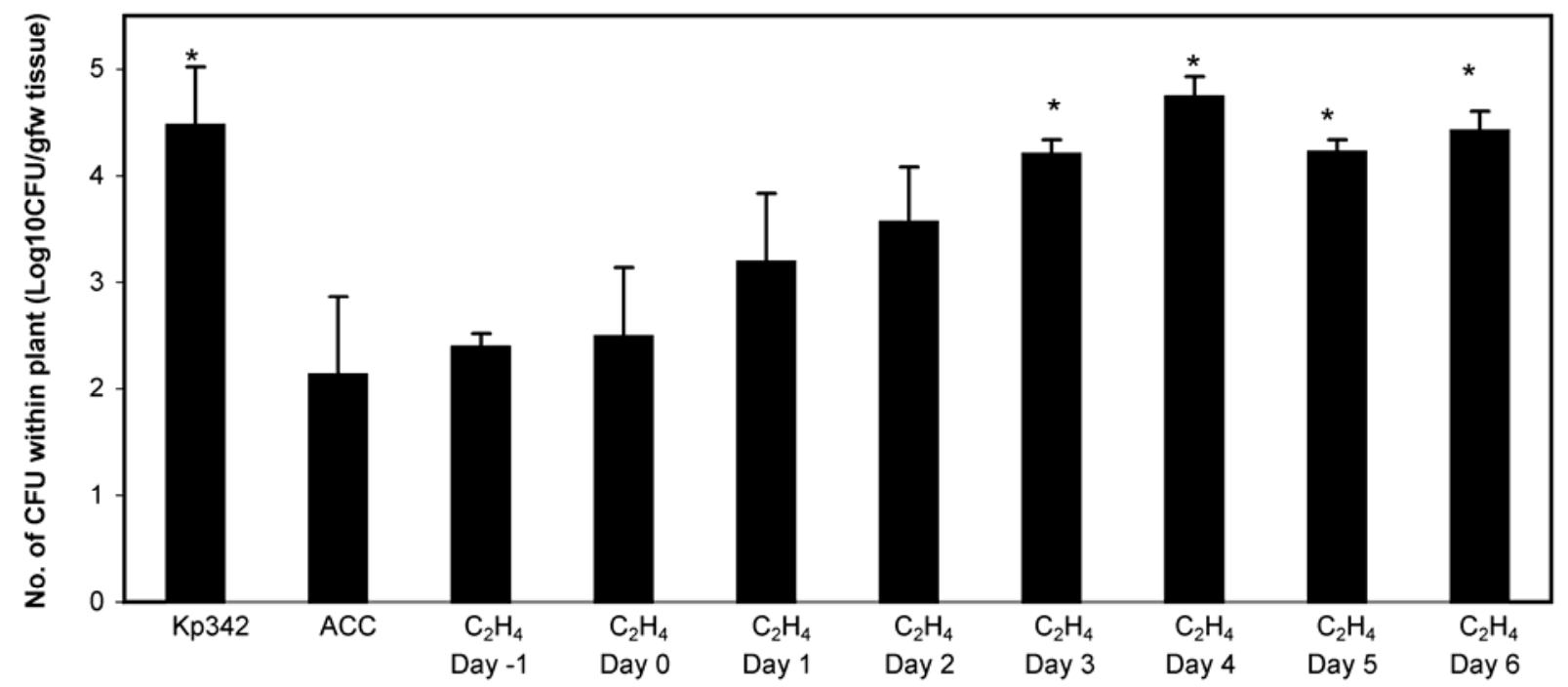

Fig. 4. Endophytic colonization of Medicago truncatula roots and hypocotyls treated with $\mathrm{C}_{2} \mathrm{H}_{4}$ on successive days. Medicago truncatula seedlings were inoculated with $10^{2}$ cells per plant of Klebsiella pneumoniae 342 (Kp342). 1-Aminocyclopropane-1-carboxylic acid (ACC) (5 $\left.\mu \mathrm{M}\right)$ was used as a control on day 0 to show that the effects of ACC and $\mathrm{C}_{2} \mathrm{H}_{4}$ are similar. $\mathrm{C}_{2} \mathrm{H}_{4}(5 \mu \mathrm{M})$ was applied to different sets of plants beginning 1 day prior to inoculation (day 1 ) and continuing each day up to 6 days after inoculation. The columns represent the mean CFU recovered from the plants 7 days post inoculation. The bars represent the standard errors of the means resulting from four replicate treatments; gfw = gram (fresh weight). Asterisks represent differences that are statistically significant from plants treated with $\mathrm{C}_{2} \mathrm{H}_{4}$ at day 0 at the $5 \%$ level of confidence.

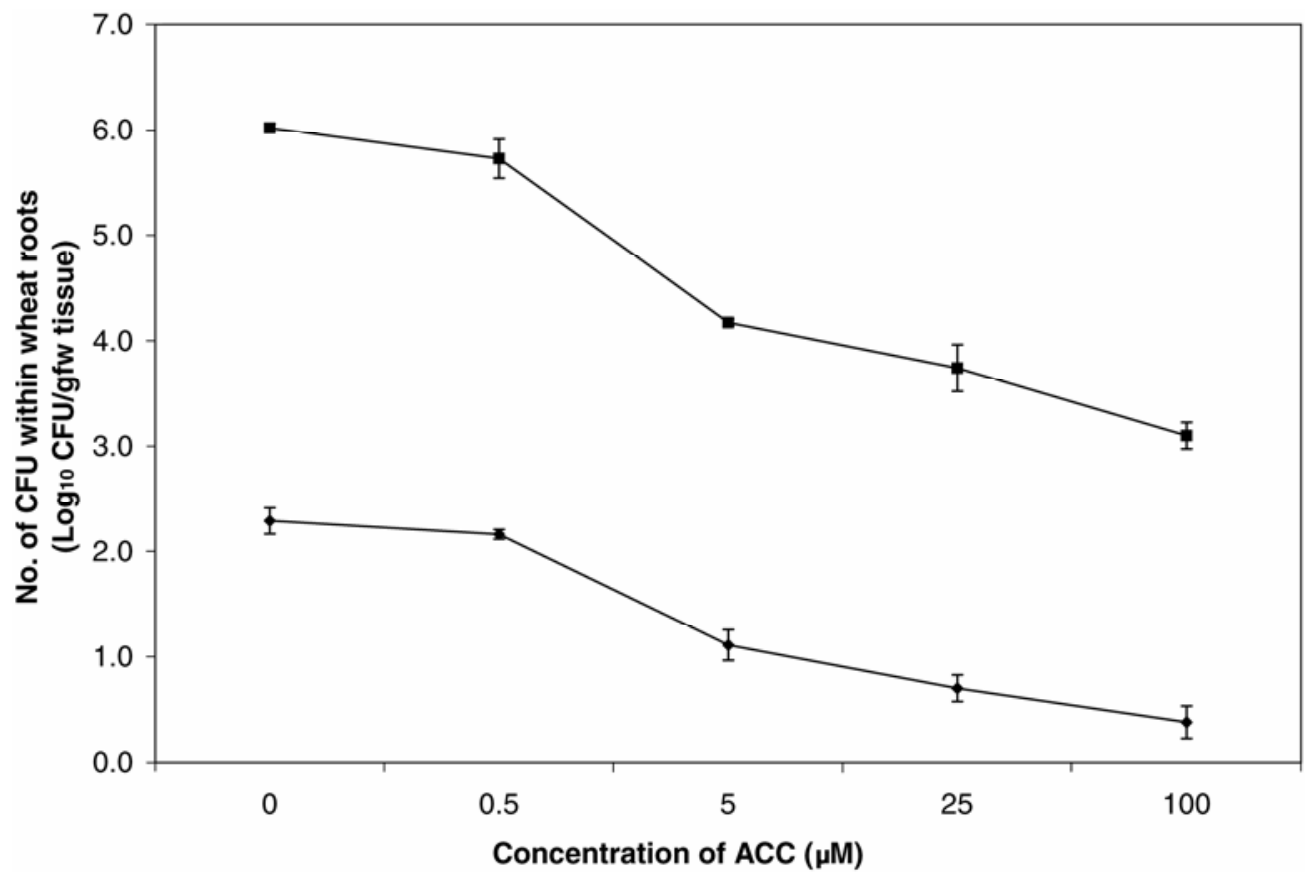

Fig. 5. Endophytic colonization of Triticum aestivum roots at in the presence of increasing concentrations of 1-aminocyclopropane-1-carboxylic acid (ACC). Number of CFU recovered from the interior of the roots and hypocotyls of wheat seedlings. Roots of 1-day-old seedlings were inoculated with $10^{4}$ cells of Salmonella enterica serovar Typhimurium strain 14028 (diamonds) and $10^{2}$ cells of Klebsiella pneumoniae 342 (squares). Plants were harvested 5 days after inoculation. The data points represent the means and the bars represent the standard errors of the means resulting from four replicate treatments. 
With the removal of these extracellular components, ethylene-mediated inhibition of endophytic colonization, although still significant, was greatly reduced compared with the wildtype strain (Fig. 2). ACC decreases endophytic colonization by over two orders of magnitude for the wild-type strain (Fig. 2), whereas the ACC-induced decrease is only 0.5 to 1.1 orders of magnitude when the seedlings were inoculated with the spaS or double flagellin mutants, respectively (Fig. 2). The Salmonella $\operatorname{sip} B$ and double flagellin mutations also caused an increase of 2.5 and 2.4 orders of magnitude, respectively, in the number of Salmonella cells within wheat roots compared with wild-type Salmonella 14028. Complementation of the sipB mutant completely reversed the increase observed from the $\operatorname{sip} B$ mutation (Fig. 2).

\section{Increased endophytic colonization} in host genotypes with diminished plant defense responses.

The importance of plant defenses on endophytic colonization were examined using Arabidopsis lines impaired in plant defense. Strain 14028, the sipB and double flagellin mutants of 14028 , and Kp342 were inoculated individually onto the roots of Arabidopsis wild-type Col-0, a nahG transgenic plant, and an $n p r l$ mutant (Fig. 7). The $n a h G$ transgenic plant produces a bacterial salicylate hydroxylase (Friedrich et al. 1995) that prevents the accumulation of SA in plants. The NPR1 protein regulates the DNA binding ability of transcription factors involved in plant defense (Despres et al. 2003; Mou et al. 2003), and the Arabidopsis nprl mutant is disrupted in both SA-mediated and SA-independent defense responses (Ton et al. 2002).

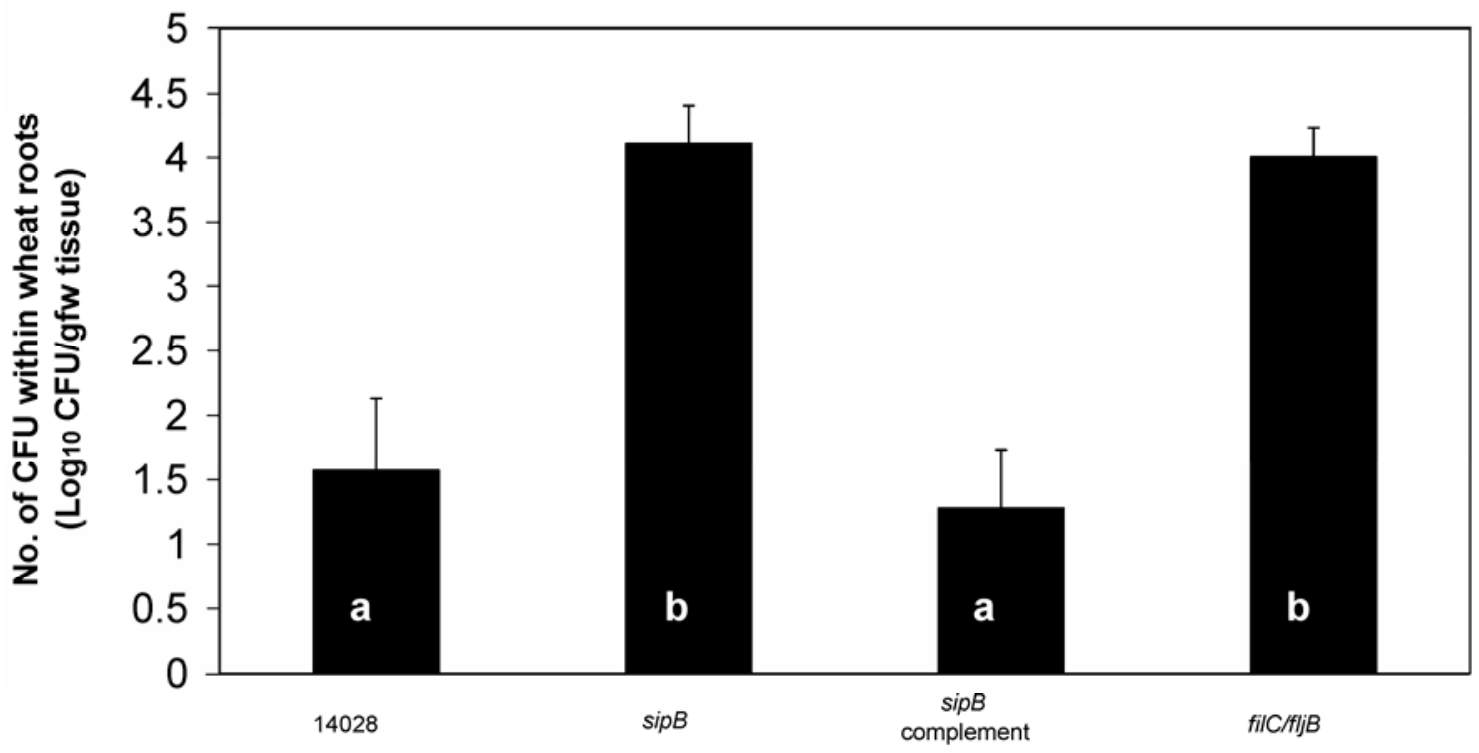

Treatments

Fig. 6. Number of CFU recovered from the interior of wheat roots and hypocotyls. Roots of 1-day-old seedlings were inoculated with $10^{4}$ cells of Salmonella enterica serovar Typhimurium strain 14028 (14028), the $\operatorname{sip} B$ mutant of 14028, the $\operatorname{sip} B$ mutant complemented with the sipB gene, and the double flagellin mutant $(f l i C / f l j B)$ of 14028 . Columns represent the means of each treatment and the bars represent the standard errors of the means resulting from four replicate treatments; $\mathrm{gfw}=$ gram (fresh weight).

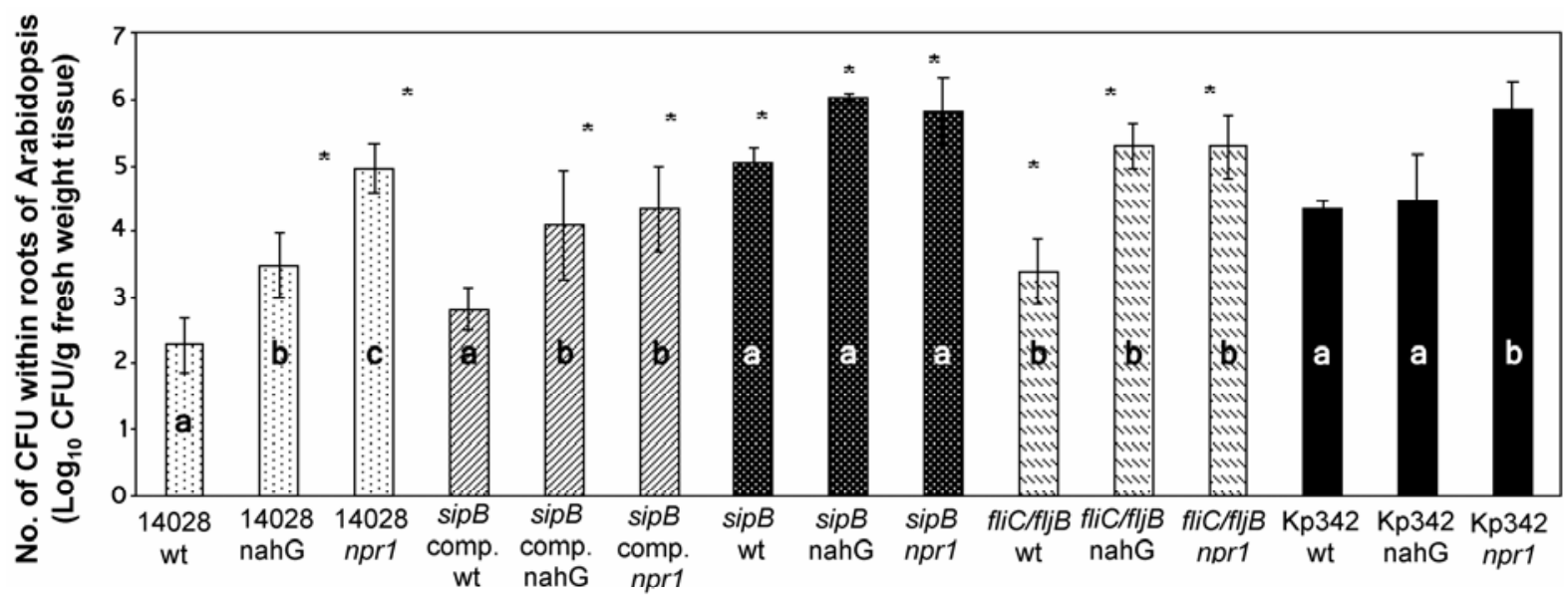

\section{Bacterial Treatment and Plant type}

Fig. 7. Root endophytic colonization of three Arabidopsis thaliana genotypes inoculated with Salmonella enterica serovar Typhimurium strain 14028 (14028), the flagella mutant of 14028, the sipB mutant of 14028, the complemented sipB mutant, and Klebsiella pneumoniae 342 (Kp342). Number of CFU recovered from the interior of roots of A. thaliana cv. wild type, nahG, and $n p r l$. The columns represent the means of each treatment. Each treatment consists of four replicates and each replicate consists of four plants. The bars represent the standard errors about the mean; gfw = gram (fresh weight). The letters in each column represent statistical differences with respect to the wild-type plant. The asterisks represent statistical differences with respect to the wild-type plant inoculated with 14028. 
Colonization by Kp342 was not significantly different on wild-type Arabidopsis spp. compared with the nahG transgenic plants, suggesting that accumulation of SA is not important for restricting colonization by Kp342. However, colonization of the nprl mutant by Kp342 was 1.5 orders of magnitude greater than in wild-type Arabidopsis spp. These data suggest that SA-independent defense responses (defective in the $n p r l$ mutant) may contribute to reduced colonization by Kp342.

The interior colonization of Arabidopsis roots by 14028 was 1.2 to 2.7 orders of magnitude greater in the nahG transgenic and nprl mutant, respectively (Fig. 7), compared with wildtype plants, suggesting that both SA-dependent and -independent pathways are involved in restricting colonization. The roles of flagellin and TTSS-SPI1 in colonization were examined by mutational analysis. Both the Salmonella double flagellin mutant $($ fliC/fljB) and the TTSS-SPI1 ( $\operatorname{sipB})$ mutants colonized the roots of wild-type Arabidopsis spp. in significantly greater numbers than the wild-type strain 14028 (Fig. 7), supporting roles for both of these extracellular components in plant recognition.

Colonization by the flagella mutant was 1.9 orders of magnitude greater in the $n a h G$ transgenic and nprl mutant than in wild-type plants (Fig. 7). For the $n a h G$ transgenic plants, these results are consistent with colonization behavior observed for 14028. However, no difference was observed in endophytic colonization of the nprl mutant by 14028 or the flagella mutant, but the wild-type host was colonized significantly more by the flagella mutant compared with 14028 . Equal colonization of the $n a h G$ transgenic and the nprl mutant by the Salmonella flagella mutant imply that endophyte recognition and the subsequent defenses induced by flagella are largely SA-independent. That is, a plant defective in SA accumulation still allows more colonization by a flagella-defective endophyte, whereas a mutant defective in both SA-dependent and -independent responses fails to exhibit super-enhanced colonization (as was observed for wild-type bacteria).

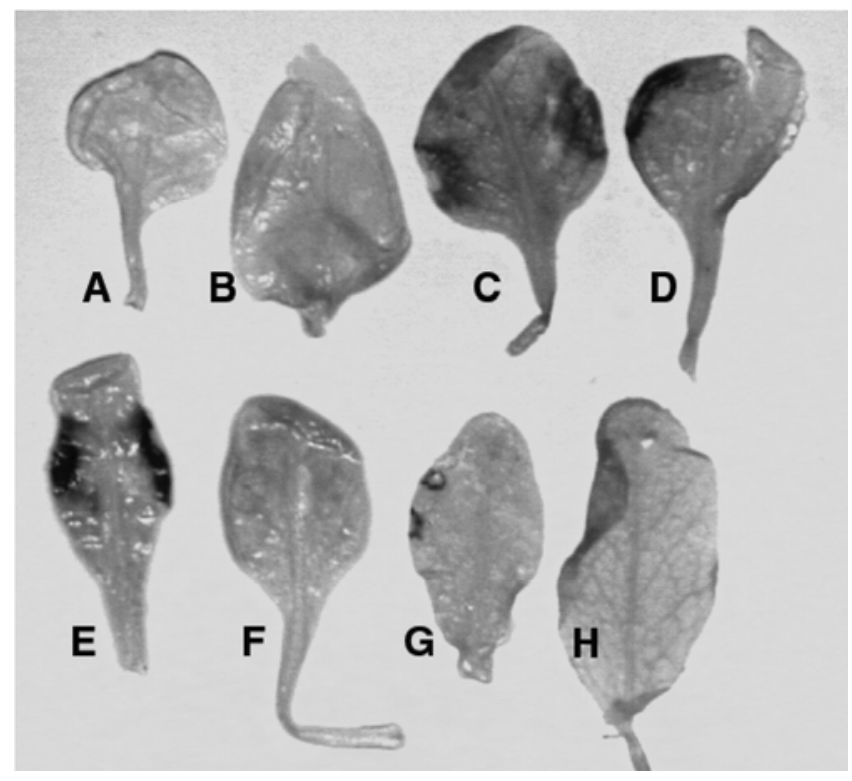

Fig. 8. Histochemical assays of A-G, Arabidopsis thaliana PR1::GUS and of $\mathbf{H}$, A thaliana wild type. The treatments were A, uninoculated, $\mathbf{B}$, inoculation with $\mathrm{H}_{2} \mathrm{O}$, C, sprayed with $5 \mathrm{mM}$ salicylic acid, D, leaves infiltrated with $10^{7} \mathrm{CFU}$ of Pseudomonas syringae DC3000, E, root inoculation with Salmonella enterica serovar Typhimurium strain 14028 (14028), F, root inoculation with the $\operatorname{sip} B$ mutant of 14028 , G, and root inoculation with the $\operatorname{sip} B$ mutant complemented with the $\operatorname{sip} B$ gene. $\mathbf{H}$, Uninoculated wild-type A. thaliana.
In contrast, data obtained with the TTSS-SPI1-defective $\operatorname{sip} B$ mutant suggest that the lack of TTSS-SPI1 effectors permits the avoidance of SA-dependent and -independent responses. Whereas colonization of wild-type plants was enhanced by the $\operatorname{sip} B$ TTSS-SPI1 mutation, colonization by $\operatorname{sip} B$ was not significantly different in $n a h G$ transgenic and $n p r l$ mutants. Therefore, although colonization by a bacterium defective in TTSSSPI1 was significantly enhanced in wild-type plants, it was unaffected by compromising both SA-dependent and -independent defense pathways in the host plant. These data suggest that $\operatorname{sip} B$-regulated TTSS-SPI1 effectors act downstream of SA and nprl in this system. As predicted, the increased colonization observed with the sipB mutant was reversed when the mutant was complemented with the wild-type gene.

These data also support the notion that the TTSS-SPI1 of 14028 induces both the SA-mediated and -independent responses, in agreement with 14028 induction of the SA-mediated PR1 promoter.

\section{Activation of a promoter that controls an SA-dependent pathogenesis-related gene upon endophyte inoculation.}

In support of the elicitation of plant defenses during endophytic colonization, the expression of the extensively studied plant defense response gene PRI (Beilmann et al. 1992) was tested by inoculation of Arabidopsis thaliana PR1::GUS with our enteric endophytes. As expected, the positive controls, application of SA or inoculation with the plant pathogen Pseudomonas syringae DC3000 PV288, strongly induced a PR1::GUS fusion in planta. The GUS activity of the $P$. syringae DC3000 PV288 and SA controls were 545 and $139 \mathrm{pmol} \mathrm{4-MU/mg} \mathrm{of}$ protein/min, respectively. Inoculation of roots with St14028 also induced PR1::GUS expression in distal leaves, displaying a GUS activity of $42 \mathrm{pmol} 4-\mathrm{MU} / \mathrm{mg}$ of protein/min, (Fig. 8). In contrast, inoculation of roots with the $\operatorname{sipB}$ mutant and Kp342 showed no GUS induction with either the qualitative in vivo or the quantitative in vitro assays. Complementation of the $\operatorname{sip} B$ mutation restored GUS expression and activity (19 pmol 4$\mathrm{MU} / \mathrm{mg}$ of protein/min) (Fig. 8). Negative controls, where plants were sprayed with $\mathrm{H}_{2} \mathrm{O}$, leaf infiltration with phosphate-buffered saline (PBS), or root inoculation with PBS failed to induce $P R 1:: G U S$ expression. Because the $P R 1$ promoter is induced by the SA signaling pathway (Stone et al. 2000), these data suggest that the TTSS-SPI1 induces SA-mediated defense signaling. Unlike 14028, inoculation with Kp342 did not result in PRI::GUS expression, suggesting that this endophyte does not induce SA-dependent defense responses (data not shown), consistent with Klebsiella spp. lacking flagella and TTSS-SPI1.

\section{DISCUSSION}

S. enterica serovar Typhimurium strain 14028, a human pathogen that does not cause disease in plants, induced both SA-dependent and -independent plant defenses. Reducing the virulence of the strain by removing TTSS-SPI1 increased endophytic colonization. The effector molecules secreted by this TTSS-SPI1 seem to be deleterious to the bacterium due to their ability to elicit both SA-mediated and -independent plant defenses. Another extracellular component, flagella, which have very little effect on virulence in animals, also induces SA-independent defense responses.

Another aspect of the strain specificity discovered here is that Kp342 is either resistant to SA-dependent responses or fails to induce them. This is based on two lines of evidence. First, nearly equal endophytic colonization of the wild-type and $n a h G$-transformed plants by Kp342 was observed. Second, inoculation with Kp342 did not induce the expression of an SA-dependent gene, PRl. Thus, some strains may be insensi- 
tive to SA-mediated responses (such as Kp342) whereas other strains (such as 14028) are sensitive to these responses. This may be a significant component of the mechanism for the strain specificity of endophytic colonization. Based on the re- sults above, both extracellular components studied here elicit SA-independent defense responses. However, only the SA-dependent defense responses elicited by TTSS-SPI1 are effective in reducing colonization.

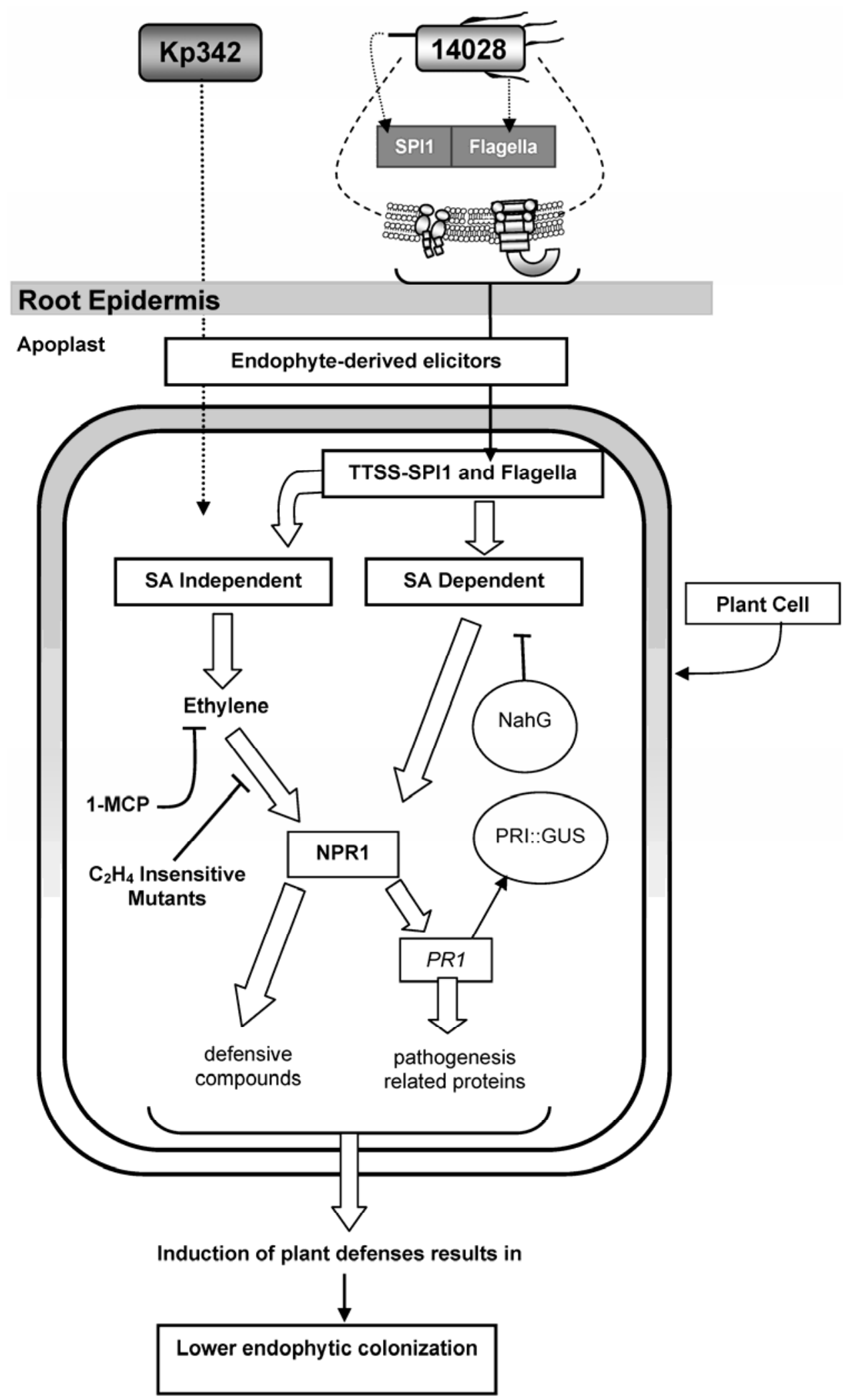

Fig. 9. Model for the regulation of the endophytic colonization of plants by enteric bacteria. Abbreviations: Kp342 = Klebsiella pneumoniae 342 , $14028=$ Salmonella enterica serovar Typhimurium strain 14028, SPI1 = Salmonella pathogenicity island 1, TTSS = type III secretion system, SA = salicylic acid, $\mathrm{NahG}=\mathrm{a}$ bacterial salicylate hydroxylase (Friedrich et al. 1995), 1-MCP $=1$-methylcyclopropene, $\mathrm{C}_{2} \mathrm{H}_{4}=$ ethylene, NPR1 = protein that regulates transcription factors involved in plant defense (Despres et al. 2003; Mou et al. 2003), and $P R 1=$ pathogenesis-related gene 1. 
This work has two significant implications that likely are broadly applicable to monocots and dicots given the similar results obtained with $A$. thaliana, $M$. sativa, $M$. truncatula, and Triticum aestivum. With regard to food safety and the presence of Salmonella spp. and other bacterial pathogens residing within plant tissue, this work suggests a means to eliminate contamination of raw produce. According to the model of Latimer and associates (2001) and based on the number of 14028 cells observed here in alfalfa tissue, human consumption of $10 \mathrm{~g}$ of 14028-contaminated, surface-sterilized alfalfa is sufficient to virtually ensure salmonellosis. This estimate assumes that the plant defenses activated by 14028 do not influence the virulence of this pathogen in humans. After induction of SA-independent defense responses with ethylene treatment, the amount of surface-sterilized fresh tissue that must be consumed by a person to cause disease increases to $30 \mathrm{~kg}$. Clearly, the induction of ethylene-mediated defense responses eliminates the possibility of illness from the consumption of contaminated tissue. However, in practice, because ethylene alters plant morphology, a means to induce these responses other than with ethylene treatment would be required in a commercial setting. A solution to this problem may be the overexpression of nprl, which is known to confer broad disease resistance in plants (Cao et al. 1998; Chern et al. 2001). Overexpression of this gene in vegetables is likely to reduce the number of enteric bacteria within plants to a level that is harmless to those who consume the raw produce.

Conversely, it may be desirable to increase the number of beneficial endophytes that enhance plant growth or nutrition. Here we show that colonization by a nitrogen-fixing endophyte is limited by SA-independent plant defense responses. Colonization of the Arabidopsis plant defense mutant (nprl) with Kp342 was significantly greater compared with the wild-type, whereas transgenic depletion of SA had no effect. Therefore, a Kp342 mutant resistant to SA-independent plant defense responses should be able to colonize plants in very high numbers.

In keeping with these observations, Kp342 lacks flagella, as do all Klebsiella spp., and TTSSs have not been identified in Kp342 (Dong et al. 2001). During the evolution of the Kp342host plant association, Kp342 may have lost extracellular com- ponents that induce SA-mediated plant defense. Alternatively, the Klebsiella sp. may have lost these components prior to any association with plants, resulting in it being a common inhabitant of plants.

For a bacterial endophyte to colonize plants in high numbers, it must be able to avoid plant defenses by failing to produce those extracellular components that elicit plant defense. Bacteria that elude plant defenses can be thought of as "stealth bacteria." The data presented here suggest that endophytic colonization may be modulated to reduce levels of harmful bacteria or enhance levels of beneficial bacteria by altering the genotypes of endophytic bacteria and their host plants.

These data suggest a model that, for a bacterial endophyte to colonize plants in high numbers, it must be able to avoid plant defenses by failing to produce those extracellular components that elicit plant defense (Fig. 9). Future experiments may show that an overexpression of plant defenses still may be able to recognize endophytic bacteria that resist wild-type levels of plant defense expression.

\section{MATERIALS AND METHODS}

Bacterial strains and inoculum preparation.

The bacterial strains used in this work are listed in Table 1. BA3104 was constructed by sequential P22 transduction into 14028 using a P22HTint lysate grown on the SL3201 $f l i C:: \operatorname{Tn} 10$ fljB::MudJ strain kindly provided by Dr. Allison O'Brien (Schmitt et al. 2001). pHC112 was constructed by amplifying the spaS gene of 14028 (nucleotides 28 to 1,327 of GenBank accession number AE008832), using Taq DNA polymerase. The spaS fragment was cloned into pCR-2.1-TOPO (Invitrogen, Carlsbad, CA, U.S.A.), removed using EcoRI, and cloned into the EcoRI site of pWSK29 (Wang and Kushner 1991). pHC113 was constructed in the same way except that the $\operatorname{sip} B$ gene was amplified (nucleotides 18,133 to 20,138 of GenBank accession number AE008831). Bacterial strains were cultured and inoculum prepared as described previously (Dong et al. 2003a and b). In some cases, very low inoculum doses were used. To be confident that we were applying such low doses, each data point consists of a minimum of four plants

Table 1. Bacterial strains used in this work ${ }^{\mathrm{a}}$

\begin{tabular}{llll}
\hline Strains & Abbreviations & \multicolumn{1}{c}{ Comments } & Reference \\
\hline Klebsiella pneumoniae 342 (Kp342) & Kp342 & Maize endophyte Kp342 & Chelius and Triplett 2000 \\
Salmonella enterica serovar Typhimurium ATCC 14028 & 14028 & Type strain provided by ATCC & ATCC \\
BA1502 (14028 spaS1502::MudJ) & spaS & TTSS SPI1 structural mutant & Ahmer et al. 1999 \\
BA1502/pHC112 & spaS complement & spaS mutant complemented with the spaS gene & This work \\
BA1577 (14028 sipB1577::MudJ) & sipB & TTSS SPI1 structural mutant & Ahmer et al. 1999 \\
BA1577/pHC113 & sipB complement & sipB mutant complemented with the sipB gene & This work \\
BA3104 (14028 fliC::Tn10 fljB::MudJ & fliClfljB & Lacks two flagellin biosynthetic genes & This work \\
Pseudomonas syringae DC3000avrRpt2 & NA & Contains avrRpt2 on plasmid PV288 & Kunkel et al. 1993 \\
\hline
\end{tabular}

${ }^{a}$ ATCC = American Type Culture Collection; TTSS SPI1 = type III secretion system of Salmonella pathogenicity island 1; NA = not available.

${ }^{b}$ Provided by Andrew Bent University of Wisconsin-Madison.

Table 2. Plants used in this work

\begin{tabular}{|c|c|c|}
\hline Plant line & Comment & Reference \\
\hline Medicago sativa cv. CUS101 & Common line for alfalfa sprout production & $\ldots$ \\
\hline M. truncatula Gaerten cv. A17 & Provided by Doug Cook, University of California, Davis & $\ldots$ \\
\hline M. truncatula mutant sickle (skl) & Provided by Doug Cook, University of California, Davis & Penmetsa and Cook 1997 \\
\hline M. truncatula Jester & Provided by Barry Rolfe, Australian National University & $\ldots$ \\
\hline M. truncatula Jermalong & Provided by Edwin Bingham, University of Wisconsin-Madison & $\ldots$ \\
\hline Arabidopsis thaliana cv. Col-0 & Arabidopsis Biological Resource Center & $\ldots$ \\
\hline A. thaliana cv. Col-0 PR1::GUS & Provided by Julie Stone University of Nebraska-Lincoln & Cao et al. 1994 \\
\hline A. thaliana cv. Col-0 nahG & Provided by Julie Stone University of Nebraska-Lincoln & Reuber et al. 1998 \\
\hline A. thaliana cv. Col-0 nprl-4 & Provided by Julie Stone University of Nebraska-Lincoln & Cao et al. 1994 \\
\hline Triticum aestivum $\mathrm{cv}$. Trenton & Hard red spring wheat line developed at North Dakota State University in 1995 & $\ldots$ \\
\hline
\end{tabular}


per replicate and four replicates per treatment in those experiments where the inoculum dose size was varied.

\section{Scanning confocal laser microscopy.}

The methodology used here for scanning confocal laser microscopy (SCLM) was previously described (Dong et al. 2003a and b). Using this methodology, hypocotyls of $M$. truncatula mutant sickle $(s k l)$ and $M$. truncatula Jermalong were observed under SCLM with $\times 20$ magnification through $\mathrm{z}$ sections ranging from 0.5 to $2 \mu \mathrm{m}$ in thickness.

\section{Seed surface sterilization, germination, inoculation, plant culture, and harvest.}

The plants used in this work are listed in Table 2. The manipulation of plants, from seed surface sterilization to plant harvest, were carried out by methods developed previously (Dong et al. 2003a and b).

\section{Determination of microbial population within surface-sterilized plant tissue.}

With the exception of the $M$. truncatula sickle experiment, where the whole plant tissue was used to determine microbial populations, only the root and hypocotyl were examined for bacterial colonization. The procedures used for surface sterilization, determination of endophytic microbial populations, and statistical analysis were done as described previously (Dong et al. 2003a and b).

\section{Assurance of endophytic colonization results.}

To ensure that the endophytic colonization numbers presented reflect only the number of cells within the interior of plant tissue, previously developed methods were followed (Dong et al. 2003a and b). Furthermore, day 0 of the time course experiment (Fig. 3) served as a control to ensure that the endophytes did not enter the plants through wounds caused during harvesting or through the root surface as a result of the surface sterilization procedure. Day 0 data show that no Kp342 cells were recovered from the interior of alfalfa seedlings within $1 \mathrm{~h}$ after inoculation. This suggests that the methods used here to estimate microbial population within plants do not contribute to endophytic invasion of the apoplast.

\section{Induction of ethylene response in seedlings.}

To induce ethylene responses, seedlings were cultured in growth medium as described previously (Dong et al. 2003a) supplemented with $5 \mu \mathrm{M}$ ACC. ACC was dissolved in water and filter sterilized prior to its addition to autoclaved plant growth media. In most experiments, seedlings were exposed to media containing ACC for $12 \mathrm{~h}$ prior to inoculation.

In the ethylene time course experiments, gaseous ethylene was added to the plants cultured in closed tubes to a final concentration of $5 \mu \mathrm{M}$. The stopper on these tubes was removed each day, flushed with fresh air, stopped, and re-treated with sufficient ethylene to bring to a final concentration of $5 \mu \mathrm{M}$.

\section{Preparation and use of 1-MCP.}

The gaseous ethylene action inhibitor, 1-MCP, was prepared and stored as described by Hall and associates (2000). 1-MCP was generated from EthylBloc, which was provided by A. B. Bleecker (University of Wisconsin, Madison, WI, U.S.A.). The concentration of 1-MCP in EthylBloc is $0.14 \%$. A stock of 1MCP of $100 \mathrm{ppm}$ was created in a serum bottle $121.5 \mathrm{ml}$ in volume. This was accomplished by adding $19.44 \mathrm{mg}$ of EthylBloc and $0.5 \mathrm{ml}$ of hot $\mathrm{H}_{2} \mathrm{O}$ to the serum bottle and setting it to rest for $15 \mathrm{~min}$. The stock was used to dispense $0.3 \mathrm{ml}$ of headspace gas to $30-\mathrm{ml}$ stopped test tubes where the plants were cultured, resulting in a final concentration of $1 \mathrm{ppm}$ per tube.
The plant cultures were placed under conditions described previously (Dong et al. 2003a and b), with the exception of a rubber stopper used to conceal 1-MCP. The stoppers were removed daily, flushed with air, stopped again, and, finally, freshly prepared 1-MCP was added to the desired final concentration.

GUS histochemical staining and GUS fluorogenic assay.

Roots of transgenic A. thaliana Col-0 harboring a pathogenesis-related 1 (PR1) gene promoter fused to the bacterial uidA ( $\beta$-glucuronidase) reporter gene (PR1::GUS) were inoculated with $10^{7} \mathrm{CFU}$ of $S$. enterica 14028 , the 14028 sipB mutant, and the complemented sipB mutant. Exogenous application of SA $(5 \mathrm{mM})$ and infiltration of leaves with $10^{7} \mathrm{CFU}$ of an avirulent strain of $P$. syringae DC3000 carrying the avrRpt2 on plasmid PV288 were used as positive controls (Kunkel et al. 1993; Ton et al. 2002). The histochemical assay was performed as described by Sundaresan and associates (1995) with slight modifications (Sundaresan et al. 1995). Plants were immersed in staining buffer ( $50 \mathrm{mM}$ sodium phosphate, $\mathrm{pH} 7,10$ $\mathrm{mM}$ EDTA, $0.1 \%$ Triton $\mathrm{X}-100$, chloramphenicol at 100 $\mu \mathrm{g} / \mathrm{ml}, 5 \mathrm{mM}$ potassium ferricyanide and 5-bromo-4-chloro-3indolyl- $\beta$-D-glucuronide (X-Glc) at $0.5 \mathrm{mg} / \mathrm{ml}$. Plants then were vacuum infiltrated, incubated overnight at $37^{\circ} \mathrm{C}$, and destained with $70 \%$ ethanol.

To conduct the quantitative GUS fluorogenic assay, whole plants were flash-frozen in liquid $\mathrm{N}_{2}$ and crushed. The fluorogenic assay and protein extraction were done as described by Jefferson and associates (1987). Protein concentration of the samples was determined using a BCA protein assay kit (Pierce, Rockford, IL, U.S.A.). GUS activity was measured as pmoles of 4-methyleunbelliferyl produced per milligram of protein per minute, abbreviated as pmol 4-MU/mg protein/min.

\section{ACKNOWLEDGMENTS}

We thank the Consortium for Plant Biotechnology Research, Cargill, Inc., Agribiotics Inc., the College of Agricultural and Life Sciences of the University of Wisconsin-Madison, and the Institute of Food and Agricultural Sciences of the University of Florida for their financial support of this work. We also acknowledge B. Ahmer from the National Institute of Allergy and Infectious Disease (grant no. 1 RO1 AI50002-04). This work was approved for publication as Journal Series No. R-10605 of the Florida Agricultural Experiment Station. This is also a contribution of the University of Nebraska Agricultural Research Division, Lincoln, NE, Journal Series No. 14428.

\section{LITERATURE CITED}

Ahmer, B. M. M., van Reeuwijk, J., Watson, P. R., Wallis, T. S., and Heffron, F. 1999. Salmonella sirA is a global regulator of genes mediating enteropathogenesis. Mol. Microbiol. 31:971-982.

Beilmann, A., Albrecht, K., Schultze, S., Wanner, G., and Pfitzner, U. M. 1992. Activation of a truncated PR-1 promoter by endogenous enhancers in transgenic plants. Plant Mol. Biol. 18:65-78.

Beuchat, L. R., Ward, T. E., and Pettigrew, C. A. 2001. Comparison of chlorine and a prototype produce wash product for effectiveness in killing Salmonella and Escherichia coli O157:H7 on alfalfa seeds. J. Food Prot. 64:152-158.

Boddey, R. M., Urquiaga, S., Alves, B. J. R., and Reis, V. 2003. Endophytic nitrogen fixation in sugarcane: Present knowledge and future applications. Plant Soil 252:139-149.

Cao, H., Li, X., and Dong, X. N. 1998. Generation of broad-spectrum disease resistance by overexpression of an essential regulatory gene in systemic acquired resistance. Proc. Natl. Acad. Sci. U. S. A. 95:6531-6536.

Chelius, M. K., and Triplett, E. W. 2000. Immunolocalization of dinitrogenase reductase produced by Klebsiella pneumoniae in association with Zea mays 1. App. Environ. Microbiol. 66:783-787.

Chern, M.-S., Fitzgerald, H. A., Yadav, R. C., Canlas, P. E., Dong, X., and Ronald, P. C. 2001. Evidence for a disease-resistance pathway in rice similar to the NPR1-mediated signaling pathway in Arabidopsis. Plant J. 27:101-113.

Collazo, C. M., and Galan, J. E. 1997. The invasion-associated type III system of Salmonella typhimurium directs the translocation of sip pro- 
teins into the host cell. Mol. Microbiol. 24:747-756.

Despres, C., Chubak, C., Rochon, A., Clark, R., Bethune, T., Desveaux, D., and Fobert, P. R. 2003. The Arabidopsis NPR1 disease resistance protein is a novel cofactor that confers redox regulation of DNA binding activity to the basic domain/leucine zipper transcription factor TGA1. Plant Cell 15:2181-2191.

Dong, Y. M., Glasner, J. D., Blattner, F. R., and Triplett, E. W. 2001. Genomic interspecies microarray hybridization: Rapid discovery of three thousand genes in the maize endophyte, Klebsiella pneumoniae 342, by microarray hybridization with Escherichia coli K12 open reading frames. Appl. Environ. Microbiol. 67:1911-1921.

Dong, Y. M., Iniguez, A. L., Ahmer, B. M. M., and Triplett, E. W. 2003a. Kinetics and strain specificity of rhizosphere and endophytic colonization by enteric bacteria on seedlings of Medicago sativa and Medicago truncatula. Appl. Environ. Microbiol. 69:1783-1790.

Dong, Y. M., Iniguez, A. L., and Triplett, E. W. 2003b. Quantitative assessments of the host range and strain specificity of endophytic colonization by Klebsiella pneumoniae 342. Plant Soil 257:49-59.

Felix, G., Duran, J. D., Volko, S., and Boller, T. 1999. Plants have a sensitive perception system for the most conserved domain of bacterial flagellin. Plant J. 18:265-276.

Friedrich, L., Vernooij, B., Gaffney, T., Morse, A., and Ryals, J. 1995. Characterization of tobacco plants expressing a bacterial salicylate hydroxylase gene. Plant Mol. Biol. 29:959-968.

Gomez-Gomez, L., and Boller, T. 2000. FLS2: An LRR receptor-like kinase involved in the perception of the bacterial elicitor flagellin in Arabidopsis. Mol. Cell 5:1003-1011.

Hall, A. E., Findell, J. L., Schaller, G. E., Sisler, E. C., and Bleecker, A. B. 2000. Ethylene perception by the ERS1 protein in Arabidopsis. Plant Physiol. 123:1449-1457.

Jefferson, R. A., Kavanagh, T. A., and Bevan, M. W. 1987. GUS fusionsbeta-glucuronidase as a sensitive and versatile gene fusion marker in higher-plants. EMBO (Eur. Mol. Biol. Organ.) J. 6:3901-3907.

Knoester, M., van Loon, L. C., van den Heuvel, J., Hennig, J., Bol, J. F., and Linthorst, H. J. M. 1998. Ethylene-insensitive tobacco lacks nonhost resistance against soil-borne fungi. Proc. Natl. Acad. Sci. U. S. A. 95:1933-1937.

Kunkel, B. N., Bent, A. F., Dahlbeck, D., Innes, R. W., and Staskawicz, B. J. 1993. RPS2, an Arabidopsis disease resistance locus specifying recognition of Pseudomonas syringae strains expressing the avirulence gene avrrpt2. Plant Cell 5:865-875

Latimer, H. K., Jaykus, L.-A., Morales, R. A., Cowen, P., and CrawfordBrown, D. 2001. A weighted composite dose-response model for human salmonellosis. Risk Anal. 21:295-306.

Mou, Z., Fan, W. H., and Dong, X. N. 2003. Inducers of plant systemic acquired resistance regulate NPR1 function through redox changes. Cell 113:935-944.

Penmetsa, R. V., and Cook, D. R. 1997. A legume ethylene-insensitive mutant hyperinfected by its rhizobial symbiont. Science 275:527-530.

Pieterse, C. M. J., van Wees, S. C. M., van Pelt, J. A., Knoester, M., Laan, R., Gerrits, N., Weisbeek, P. J., and van Loon, L. C. 1998. A novel signaling pathway controlling induced systemic resistance in Arabidopsis. Plant Cell 10:1571-1580.

Porat, R., Weiss, B., Cohen, L., Daus, A., Goren, R., and Droby, S. 1999.
Effects of ethylene and 1-methylcyclopropene on the postharvest qualities of 'shamouti' oranges. Postharvest Biol. Technol. 15:155-163.

Proctor, M. E., Hamacher, M., Tortorello, M. L., Archer, J. R., and Davis, J. P. 2001. Multistate outbreak of Salmonella serovar Muenchen infections associated with alfalfa sprouts grown from seeds pretreated with calcium hypochlorite. J. Clin. Microbiol. 39:3461-3465.

Riggs, P. J., Chelius, M. K., Iniguez, A. L., Kaeppler, S. M., and Triplett, E. W. 2001. Enhanced maize productivity by inoculation with diazotrophic bacteria. Aust. J. Plant Physiol. 28:829-836.

Schmitt, C. K., Ikeda, J. S., Darnell, S. C., Watson, P. R., Bispham, J., Wallis, T. S., Weinstein, D. L., Metcalf, E. S., and O'Brien, A. D. 2001 Absence of all components of the flagellar export and synthesis machinery differentially alters virulence of Salmonella enterica serovar Typhimurium in models of typhoid fever, survival in macrophages, tissue culture invasiveness, and calf enterocolitis. Infect. Immun. 69:56195625

Serek, M., Tamari, G., Sisler, E. C., and Borochov, A. 1995. Inhibition of ethylene-induced cellular senescence symptoms by 1-methylcyclopropene, a new inhibitor of ethylene action. Physiol. Plant. 94:229-232.

Sevilla, M., Burris, R. H., Gunapala, N., and Kennedy, C. 2001. Comparison of benefit to sugarcane plant growth and ${ }^{15} \mathrm{~N}_{2}$ incorporation following inoculation of sterile plants with Acetobacter diazotrophicus wildtype and nif mutant strains. Mol. Plant-Microbe Interact. 14:358-366.

Stone, J. M., Heard, J. E., Asai, T., and Ausubel, F. M. 2000. Simulation of fungal-mediated cell death by fumonisin b1 and selection of fumonisin b1-resistant (fbr) Arabidopsis mutants. Plant Cell 12:1811-1822.

Sundaresan, V., Springer, P., Volpe, T., Haward, S., Jones, J. D. G., Dean, C., Ma, H., and Martienssen, R. 1995. Patterns of gene-action in plant development revealed by enhancer trap and gene trap transposable elements. Genes Dev. 9:1797-1810.

Taormina, P. J., Beuchat, L. R., and Slutsker, L. 1999. Infections associated with eating seed sprouts: An international concern. Emerg. Infect. Dis. 5:626-634.

Ton, J., Davison, S., Van Wees, S. C. M., Van Loon, L. C., and Pieterse, C. M. J. 2001. The Arabidopsis isr1 locus controlling rhizobacteria-mediated induced systemic resistance is involved in ethylene signaling. Plant Physiol. 125:652-661.

Ton, J., De Vos, M., Robben, C., Buchala, A., Metraux, J. P., Van Loon, L. C., and Pieterse, C. M. J. 2002. Characterization of Arabidopsis enhanced disease susceptibility mutants that are affected in systemically induced resistance. Plant J. 29:11-21.

Wang, R. F., and Kushner, S. R. 1991. Construction of versatile low-copynumber vectors for cloning, sequencing and gene-expression in Escherichia coli. Gene 100:195-199.

Weissinger, W. R., and Beuchat, L. R. 2000. Comparison of aqueous chemical treatments to eliminate Salmonella on alfalfa seeds. J. Food Prot. 63:1475-1482.

Weissinger, W. R., McWatters, K. H., and Beuchat, L. R. 2001. Evaluation of volatile chemical treatments for lethality to Salmonella on alfalfa seeds and sprouts. J. Food Prot. 64:442-450.

Zhang, S. P., Kingsley, R. A., Santos, R. L., Andrews-Polymenis, H., Raffatellu, M., Figueiredo, J., Nunes, J., Tsolis, R. M., Adams, L. G., and Baumler, A. J. 2003. Molecular pathogenesis of Salmonella enterica serotype Typhimurium-induced diarrhea. Infect. Immun. 71:1-12. 